\title{
Vulnerability Assessment of Water Environmental System in Beijing-Tianjin-Hebei (BTH) Region
}

\author{
Xiao-Hua YANG* \\ School of Environment, Beijing Normal University, \\ Beijing, 100875, China \\ e-mail: xiaohuayang@bnu.edu.cn \\ Bo-yang SUN \\ School of Environment, Beijing Normal University, \\ Beijing, 100875, China \\ Yi YE \\ School of Environment, Beijing Normal University, \\ Beijing, 100875, China
}

\author{
Yuan XIE \\ School of Environment, Beijing Normal University, \\ Beijing, 100875, China
}

Mei-shui LI

School of Environment, Beijing Normal University, Beijing, 100875, China

Yu-qi LI

Colleges of Architecture and Landscape Architecture, Peking University, Beijing, 100871, China e-mail: angela930909@sina.com

\begin{abstract}
Rapid population growth and increased economic activity impose an urgent challenge on the sustainability of water environmental system in Beijing - Tianjin - Hebei (BTH) region. Water environmental system is a complex uncertain system under change which is of vulnerability. But water environmental system vulnerability research is relatively weak. In this study, we present a multifunctional hierarchy indicator system for the performance evaluation of water environmental vulnerability (WEV). This paper constructed the assessment index system of water environment system based on PSR model which contained 24 indicators considering social-economy conditions and situation of water resources. Weights were calculated by the method of analytic hierarchy process (AHP) and entropy, and fuzzy set pair analysis assessment method (FSPAAM) was applied to evaluate the degree of vulnerability in the Beijing - Tianjin - Hebei region. The vulnerability degree in Beijing was from III to II, while in Tianjin was mostly III (except IV in 2013), and in Hebei was all III. Finally, we make some suggestions for water environmental management in BTH.
\end{abstract}

Keywords-Water environment vulnerability; Beijing Tianjin - hebei; Assessment; Indicator system; Fuzzy set pair analysis

\section{INTRODUCTION}

Water environmental system plays a significant role in regional sustainable development. The influencing factors to water environmental vulnerability are various. These factors influence each other and constitute a system which has the features of hierarchy, uncertainty and complexity [1]. So, the assessment of water environmental vulnerability is the process of multiple objective decision-makings, in which mathematics model needs to be established to provide scientific basis for the sustainable water environmental management. General assessment methods included fuzzy set theory, artificial neural network model, analytic hierarchy process and so on [2-4]. Those assessment methods have some difficulties for assessing complex uncertain water resources system vulnerability rationally. Set pair analysis (SPA) theory was proposed by Keqin Zhao in $1989[5,6]$. The theory has advantage to deal with uncertainties compared with other models. Therefore, to solve the above uncertain complexity assessment problems of water environmental vulnerability, we first establish a hierarchy indicator system for the performance assessment of water environmental vulnerability (WEV) based on the Pressure-State-Response (PSR) model. And then we build an fuzzy set pair analysis assessment method (FSPAAM) for assessing water environmental vulnerability, in which weights are determined by the analytic hierarchy process (AHP) and entropy method, and the assessment degrees are determined by the fuzzy set pair analysis (SPA) theory. Finally, FSPAAM is used to assess the degree of water environmental vulnerability in Beijing, Tianjin and Hebei region.

\section{FuZZy Set PaIR ANALysis ASSESSMENT Method (FSPAAM) FOR WEV ASSESSMENT}

We propose a multiple criteria decision making method on water environmental vulnerability (WEV) assessment. It includes the assessment indicator system and assessment criteria. The index system was established with 24 indicators based on Pressure-State-Response (PSR) model. The indicators are shown in Table 1.The construction of assessment index system is divided into four steps. First, select appropriate indices based on the PSR model. Second, the degree of water environmental vulnerability can be divided into 5 grades: lowest (1), lower (2), middle (3), higher (4), highest (5). Finally, we gave an assessment method for WEV. In this study, we gave a fuzzy set pair analysis assessment method (FSPAAM) for WEV assessment. Weights were calculated by the method of 
analytic hierarchy process (AHP) and entropy. And fuzzy set pair analysis assessment method (FSPAAM) was applied to evaluate the degree of vulnerability in Beijing, Tianjin and Hebei (BTH) regions. Figure 1 shows the basic flow path in the process of fuzzy set pair analysis assessment method (FSPAAM) for WEV assessment.

TABLE I. THE ASSESSMENT INDICATOR SYSTEM

\begin{tabular}{|c|c|c|}
\hline Pressure index & State index & Response index \\
\hline $\begin{array}{l}\text { No.1 Amount of water } \\
\text { resources per unit area }\end{array}$ & $\begin{array}{c}\text { No.8 Emission concentration } \\
\text { of } \mathrm{NH}_{3}-\mathrm{N}\end{array}$ & $\begin{array}{l}\text { No.16 The capacity of Industrial } \\
\text { wastewater treatment }\end{array}$ \\
\hline $\begin{array}{l}\text { No.2 Utilization ratio of } \\
\text { water resources }\end{array}$ & $\begin{array}{c}\text { No.9 Emission concentration } \\
\text { of } \mathrm{COD}\end{array}$ & $\begin{array}{l}\text { No. } 17 \text { Proportion of agricultural } \\
\text { water-saving irrigation area }\end{array}$ \\
\hline $\begin{array}{l}\text { No. } 3 \text { Ten-thousand yuan } \\
\text { GDP water consumption }\end{array}$ & No. 10 Green coverage rate & No.18 Proportion of ecological water \\
\hline $\begin{array}{c}\text { No.4 The discharge of } \\
\text { domestic sewage per person }\end{array}$ & $\begin{array}{l}\text { No.11 Consumption of daily } \\
\text { water per person }\end{array}$ & $\begin{array}{l}\text { No.19 Proportion of water and soil } \\
\text { erosion control area }\end{array}$ \\
\hline $\begin{array}{l}\text { No. } 5 \text { Average annual } \\
\text { precipitation }\end{array}$ & $\begin{array}{l}\text { No. } 12 \text { The average person } \\
\text { possession of water }\end{array}$ & No.20 Environment investment ration \\
\hline $\begin{array}{c}\text { No.6 Floods affected area } \\
\text { ratio }\end{array}$ & No.13 Wetland area ratio & No.21 Industrial water recycling rate \\
\hline \multirow[t]{2}{*}{$\begin{array}{l}\text { No.7 Proportion of } \\
\text { agricultural water use }\end{array}$} & No.14 Population density & No.22 Urban sewage treatment rate \\
\hline & No. 15 Per capita GDP & $\begin{array}{l}\text { No.23 The capacity of sewage treatment } \\
\text { No. } 24 \text { The sound level of the legal system }\end{array}$ \\
\hline
\end{tabular}

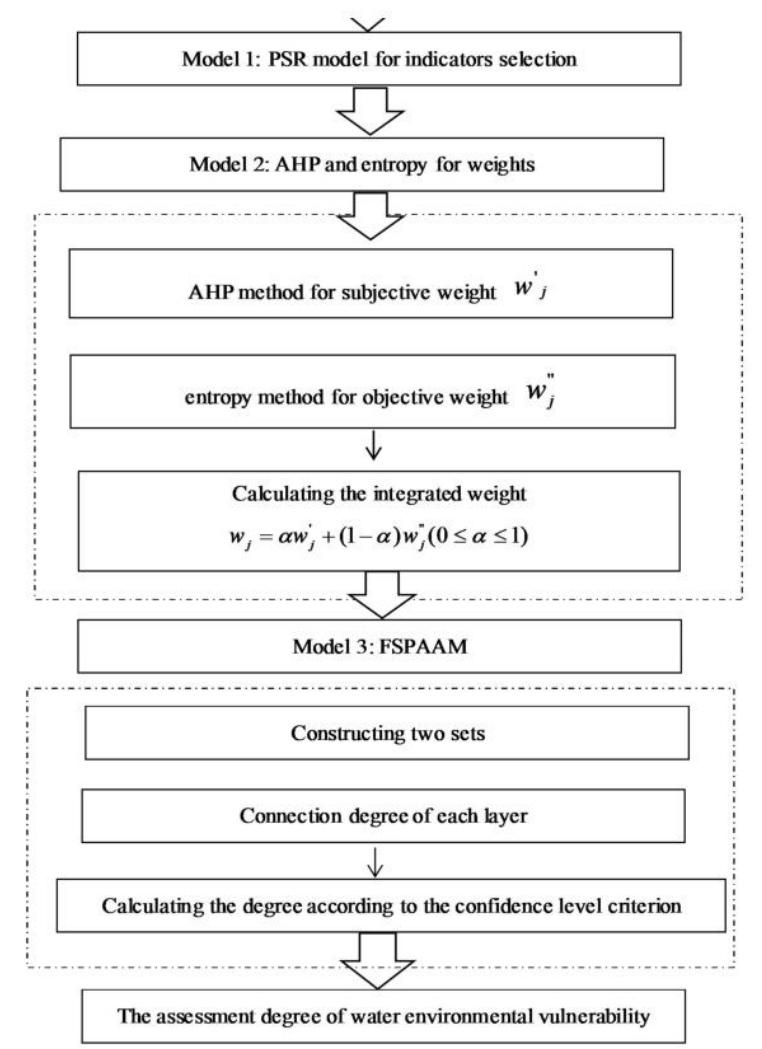

Figure 1. Fuzzy set pair analysis assessment method (FSPAAM) for WEV assessment

\section{CASE STUDY}

In this study, we use Beijing-Tianjin-Hebei (BTH) region as a case. BTH is the nation's political, economic and cultural center in China. With the rapid increase of population, the acceleration of urbanization and the rapid development of economy and society, the water environment become more and more severe, especially during the past decades. And the same time, precipitation is one of the most important factors related with climate and water environment system. All the data are from The Editorial Board of The Blog of China Environment, China Statistical Yearbook, and the National Climate Center (NCC) of the China Meteorological Administration (CMA) in this study. Table 2 gives the grades of vulnerability in Beijing, Tianjin and Hebei by using the above fuzzy set pair analysis assessment method (FSPAAM).

TABLE II. The GRADES OF VULNERABILITY IN BEIJING, TIANJIN AND HEBEI

\begin{tabular}{cccc}
\hline Time & Beijing & Tianjin & Hebei \\
\hline 2010 & 3 & 3 & 3 \\
2011 & 3 & 3 & 3 \\
2012 & 2 & 3 & 3 \\
2013 & 2 & 4 & 3 \\
2014 & 2 & 3 & 3 \\
\hline
\end{tabular}

Table 2 shows the grades of vulnerability in Beijing, Tianjin and Hebei was getting better. To be specific, the degree of vulnerability in Beijing was from III (middle) to II(lower), while in Tianjin was III(middle)mostly (except IV in 2013), and in Hebei was all III(middle). It reflects that the situation of water environment in Beijing shows a trend of improvement, while the grades in Tianjin and Hebei remain stable. In order to improve the situation, it is necessary to build a water-saving society, develop unconventional water resources and strengthen the protection of water environmental system.

\section{CONCLUSION}

In this study, we present a hierarchy indicator system for the assessment of water environment vulnerability. We gave a fuzzy set pair analysis assessment method (FSPAAM) for WEV assessment. Weights were calculated by the method of analytic hierarchy process (AHP) and entropy. And fuzzy set pair analysis assessment method (FSPAAM) was applied to evaluate the degree of vulnerability in Beijing, Tianjin and Hebei (BTH) regions. And the main conclusions are as follows:

(1) The degree of vulnerability in Beijing was from III to II, while in Tianjin was III mostly (except IV in 2013), and in Hebei was all III.

(2) Compared with present situation, the degree of vulnerability in Beijing-Tianjin-Hebei Region was getting better due to efficient measures like decline in water consumption.

(3) For further improvements, it is necessary to build a water-saving society, develop unconventional water resources and impel the integration of water environment protection in the three regions. 


\section{ACKNOWLEDGMENT}

This work was supported by the Project of National Natural Foundation of China (No.51379013, 51679007), and the State Key Program of National Natural Science of China (No. 41530635).

\section{REFERENCES}

[1] C.J. Vorosmarty, Global water resources: vulnerability from climate change and population growth, Science, 289, 5477 (2000), pp. 284-288.

[2] B.L. Han, H.X. Liu, and R.S. Wang. Urban ecological security assessment for cities in the Beijing-Tianjin-Hebei metropolitan region based on fuzzy and entropy methods, Ecological Modelling, 318(2015), pp.217-225.

[3] L.S. Iliadis and F. Maris, An artificial neural network model for mountainous water-resources management: The case of cyprus mountainous watersheds, Environ. Modell. Softw., 22 (2007), pp.1066-1072.

[4] T.L. Saaty, Time dependent decision-making; dynamic priorities in the AHP/ANP: Generalizing from points to functions and from real to complex variables, Mathematical and Computer Modelling, 46 (2007), pp.860-891.

[5] K.Q. Zhao, Set Pair Analysis and Its Application (Zhejiang Science and Technology Press, 2000).

[6] X.H. Yang, et al. Nonlinear optimization set pair analysis model (NOSPAM) for assessing water resource renewability, Nonlinear Processes Geophys.,18,5 (2011),pp.599-607. 